\title{
La Habana: \\ dinámica socio espacial de las formas urbanas
}

\begin{abstract}
René A. González Rego ${ }^{1}$
Resumen: Se presentan una serie de apuntes y reflexiones del autor en torno a la dinámica de las formas urbanas en La Habana, enfatizándose en las incidencias socio-espaciales del triunfo de la revolución de enero de 1959 a tenor de las peculiaridades del modelo socialista de asimilación socio espacial, situación que permaneció al menos desde el punto de vista teórico intacto o al menos inamovible hasta la década de los noventa del siglo pasado con el comienzo de una profunda y perdurable crisis económica. El peculiar modelo cubano para salir de la crisis, presenta matices en su impacto sobre la estructura socio espacial y las formas urbanas en la ciudad, incluyendo la apuesta al desarrollo del turismo internacional, un reto importante dada su incidencia en la creación de realidades que llevan aparejadas a la restauración y aparición de nuevas y diversas formas urbanas la re funcionalización de las memorias urbanas.
\end{abstract}

Palabras-clave: dinámica socio espacial; formas urbanas; memoria urbana, patrimonio urbano; espacio edificado

\section{Havana: \\ dinâmica socio-espacial das formas urbanas}

Resumo: Apresenta-se uma série de questões e reflexões do autor acerca da dinâmica das formas urbanas em Havana, com ênfase nas incidências socio-espaciais do triunfo da Revolução em janeiro de 1959, regido pelas peculiaridades do modelo socialista de assimilação socio-espacial, situação que permaneceu ao menos desde o ponto de vista teórico imóvel até a década noventa do século passado com o começo de uma profunda e perdurável crise económica. O modelo peculiar cubano para sair da crise apresenta matrizes no seu impacto sobre a estructura socio-espacial e as formas urbanas na cidade, incluindo a aposta ao desenvolvimento do turismo internacional, um grande desafio dada a sua incidência na criação de realidades paralelas a restauração e aparição de novas e diversas formas urbanas e a reactivação das memórias urbanas.

Palavras-chave: dinâmica socio-espacial, formas urbanas, memória urbana, património urbano, espaço edificado

\section{Havana: \\ socio-spatial dynamics of city form}

\begin{abstract}
A series of notes and reflections of the author about the dynamics of urban forms in Havana are presented; emphasizing in the socio-spatial incidences of the triumph of the Revolution of January 1959 according to the peculiarities of the socialist model of assimilation socio- spatial. This situation remained intact at least from the theoretical point of view or at least immovable until the nineties of the last century with the beginning of a deep and enduring economic crisis. The peculiar Cuban model to emerge from the crisis presents nuances in its impact on the socio-spatial structure and urban forms in the city, including the commitment to the development of international tourism, an important challenge given its impact on the creation of realities that, with the restoration and appearance of new and diverse urban forms, bring along the re-functionalization of urban memories.
\end{abstract}

Keywords: socio-spatial dynamics; City form; Urban memory; Urban patrimony; Spaces developed

Recebido: janeiro de 2018. Aceite: março de 2018.

${ }^{1}$ Doutor em Ciências Geográficas pela Universidad de La Habana. Email: rgrego@geo.uh.cu. 


\section{Introducción}

Se presentan una serie de apuntes y reflexiones del autor en torno a la incidencia que en la conformación de la memoria urbana de $\mathrm{La}$ Habana ha tenido la dinámica de las formas urbanas a partir del siglo XX y hasta la primera década del siglo XXI, enfatizándose en el análisis de las incidencias socio-espaciales del triunfo de la revolución de enero de 1959 a tenor de las peculiaridades del modelo socialista de asimilación socio espacial, proyectándose hacia un proceso de acumulación, integración y sobre imposición de elementos sociales, situación que permaneció al menos desde el punto de vista teórico intacto o al menos inamovible hasta la década de los noventa del siglo pasado, momento en que el país se sume en un profunda y perdurable crisis económica que marca el inicio de un nuevo proceso de recomposición o reacomodamiento social del espacio edificado en el que el desarrollo del turismo como actividad económica ha jugado un papel preponderante.

Si se parte de la convicción de que el "espacio geográfico" es una categoría que se construye socialmente y que posee la propiedad de presentarse ante nosotros como expresión de patrimonio, de la historia precedente y actual, de una memoria, entonces es pertinente la utilización de dicha categoría geográfica en el tema de la dinámica socio espacial de las formas urbanas, permitiendo tener en cuenta que toda ciudad, vista en un momento determinado, constituye un reflejo de la sociedad en que se desarrolla la misma, siendo la manifestación de sus formas urbanas un reflejo del funcionamiento de dicha organización social.

El espacio urbano actual es el resultado de un proceso de diferenciación socio espacial, que obedece a los procesos económicos y sociales ocurridos en el pasado y el presente. La ciudad fortalece y/o reacomoda memoria de su proceso histórico de consolidación espacial, a la vez que pueden re-emerger o emerger nuevas disparidades de manera coyuntural.

La Habana, como todo asentamiento humano en el transcurso de conversión en gran ciudad, ha presentado un proceso de asimilación espacial discontinuo y heterogéneo, incidiendo en la conformación de su patrimonio diversos factores, que van desde los naturales hasta los de carácter socioeconómicos.

De hecho, en el transcurso de su desarrollo histórico-espacial puede plantearse la presencia de espacios y formas urbanas diferenciadas, que han cumplido, o cumplen una función determinada en respuesta a los procesos sociales vividos en el pasado y el presente. Unos breves apuntes históricos de la dinámica espacial de La Habana durante la primera mitad del siglo XX, momento en que se manifiesta ya su contundente terciarización (servicios al turismo internacional, comercio, actividad bancaria, hoteles, etc.) brinda los necesarios antecedentes para la comprensión de los procesos de transformación del patrimonio edificado desarrollado a partir del triunfo revolucionario de 1959, matizándose a posteriori dicho periodo según el accionar de la dinámica económica, política y social a escala nacional, a saber;

\section{La primera mitad del siglo $\mathrm{XX}$}

En los primeros años del siglo $\mathrm{XX}$ comienza a destacarse el carácter comercial y administrativo que asume la zona central de la ciudad bajo el giro de las actividades financieras y comerciales que comenzaban a desarrollarse con los Estados Unidos de Norteamérica, jugando de conjunto un papel decisivo en la conformación del espacio social capitalino; instalándose en el centro urbano tradicional sucursales bancarias, las oficinas de seguros, edificios de oficinas, el comercio al por mayor y al detalle, así como sus principales hoteles, algunos provenientes del siglo anterior, a saber; Hotel Telégrafo (1835); Perla de Cuba (1835); Del Comercio (1841); La Unión (1846); Inglaterra (1856); Pasaje (1877); Saratoga (1879); Roma (1881); Isla de Cuba (1888); en la última década del siglo XIX (Trotcha, Brooklyn, Fornos, Plaza).

En zonas de nueva urbanización como El Vedado, si bien se trató de conservar una estricta segregación espacial a favor de los grupos sociales de mayores recursos esto no se logró, dada la coexistencia de lujosos inmuebles con viviendas de madera y precarias, a lo que se une la congelación especulativa de solares yermos en espera de su revalorización, fenómeno que se materializa posteriormente en la década de 1950 con la construcción de torres de viviendas para la propiedad horizontal.

Dadas estas razones de "mezcla social" se torna necesario para las clases pudientes la búsqueda de nuevas zonas de expansión hacia territorios "no contaminados socialmente" y "con valores paisajísticos", siguiendo las directrices costeras hacia el oeste y este (figura.1), direcciones que se constituyen en ejes fundamentales del asentamiento de los grupos poblacionales de mayores ingresos, situación que lleva aparejada la creación de formas urbanas vinculadas al desarrollo del sector terciario, incluyendo el turismo y el ocio, por ejemplo, la construcción de hoteles (Hotel Plaza 1908; Hotel Ohio 1917; Hotel Lafayette 1919; Hotel New York 1919; Hotel Presidente 1927; Hotel Nacional 1928; Hotel Sevilla). 
Para reafirmar la diferenciación socio espacial imperante en la capital cubana son elocuentes las palabras del gran físico alemán Albert Einstein, quien a finales de 1930 visitaba la ciudad y expresaba en su diario su visión acerca de dicha situación: "(...) Clubes lujosos al lado de una pobreza atroz, que afecta principalmente a las personas de color (...)" (Altshuler, 1990), siendo la Ciudadela ${ }^{i}$, formas urbanas que aún perduran, una de las expresiones más fieles de la vivienda de las personas de menores recursos en La Habana, en las cuales proliferaba el hacinamiento, la promiscuidad y la convivencia, en contraste con las sólidas mansiones de los grupos sociales de mayores recursos que ya comenzaban a proliferar.

El desarrollo de la iniciativa privada es otro elemento que contribuye a acelerar el proceso de crecimiento y diferenciación social de la mancha urbana hacia el oeste del centro urbano (hacia el término municipal de Marianao), dado por asumir, tanto el desarrollo de las infraestructuras básicas a escala comunitaria (sobre todo con la finalidad de satisfacer las necesidades creciente de selectos grupos sociales), como por su inversión hacia sectores ya identificados por las actividades turísticas y recreativas de los grupos sociales dominantes y de los visitantes extranjeros (norteamericanos fundamentalmente), destacándose en este caso el sector norte occidental costero de la ciudad.

\section{- Continua la Expansión hacia el} oeste de las parcelaciones para uso residencial más exclusivas; Así por ejemplo, se compactó el barrio de Miramar, zona ubicada en la sección del primer nivel de terrazas marinas, con presencia de baja densidad habitacional, calles bien trazadas y manzanas más grandes en el que se asientan elementos de la más alta aristocracia,

- Diseminación de repartos residenciales hacia zonas de interés urbanístico, los cuales se caracterizan por presentar una buena estructura urbanística, y la presencia de viviendas individuales con alto confort y estética, ocupadas por una extensa clase media existente en la capital.

- $\quad$ Se extienden hacia la periferia aquellas parcelaciones desarrolladas en zonas donde el bajo valor del suelo urbano, dadas las limitaciones del medio físico y las distancias al centro, condicionaron que no tuvieran mayor demanda inmobiliaria, esta situación promueve la ocupación de las mismas por grupos sociales de bajos ingresos e inmigrantes de diferentes zonas del país, así como de aquellos provenientes del proceso de erosión del centro histórico, caracterizándose estas zonas por viviendas de bajo valor arquitectónico y una urbanización mal estructurada.

Figura 1. Directrices de crecimiento según modelo digital de elevación. La Habana.

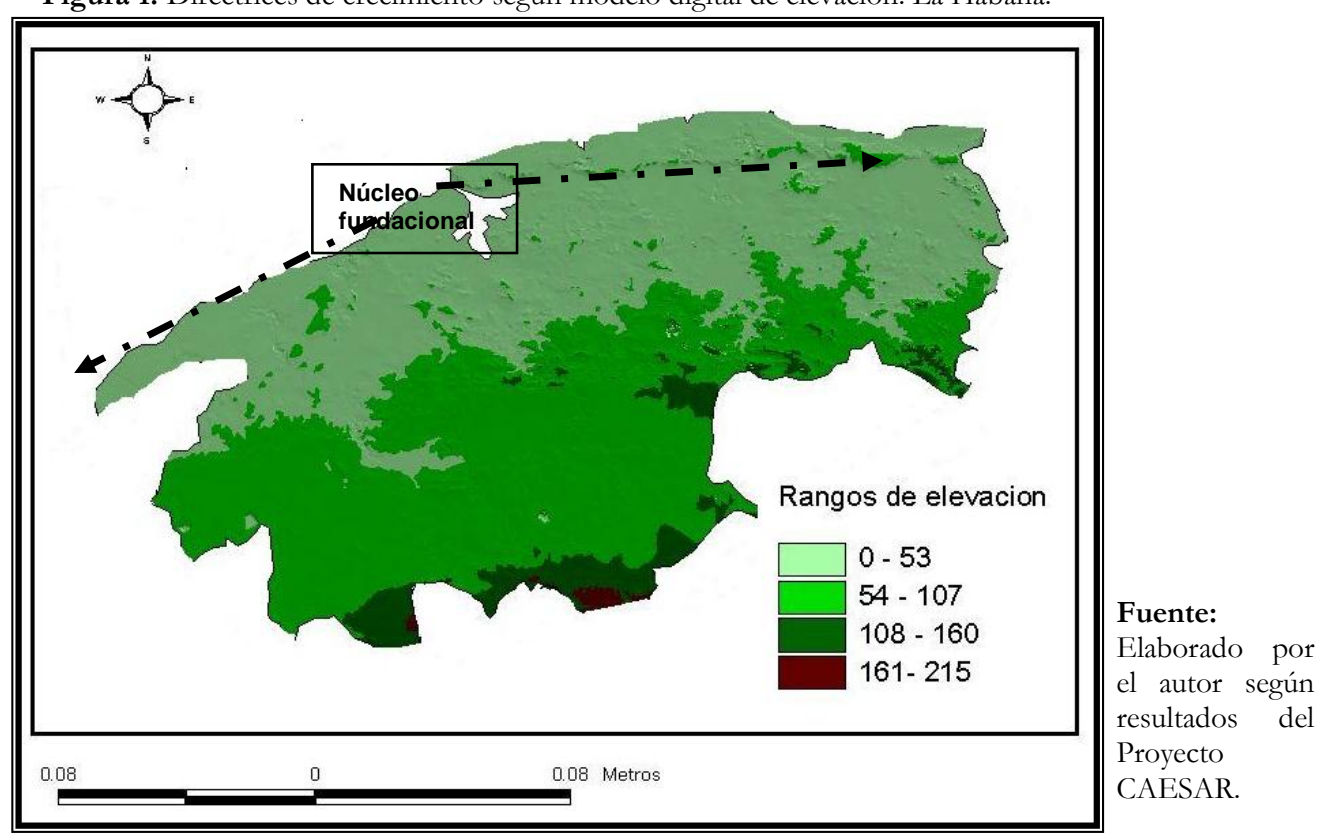

Entre los años 1945 y 1958 se acentúa el proceso de diferenciación socio espacial habanero al coincidir este intervalo de tiempo con el de mayor auge de su proceso de urbanización, continuando el desarrollo del modelo de segregación ya existente, a saber;
- $\quad \mathrm{Al}$ mismo tiempo se produce la proliferación de urbanizaciones precarias, se desarrollan fundamentalmente en los espacios que quedaban libres de urbanización en el desarrollo del proceso de poblamiento asociado a la dirección de crecimiento de los principales ejes viales, así 
como en áreas que presentaban condiciones no idóneas para el hábitat, en ocasiones próximos a industrias o proyectos de construcción dada la posibilidad de encontrar algún empleo casual, siendo de hecho la población que allí residía la más marginada, no sólo desde el punto de vista espacial, sino de condiciones de vida.

La evolución económica de la ciudad, basada fundamentalmente en el desarrollo del comercio (sustentado tanto en el capital nacional como extranjero), convierte parte del territorio del centro urbano ii tradicional en el eje de las actividades comerciales y de servicios de todo tipo, respaldando la intensa vida que se iba gestando en su entorno, así a lo largo de las calles Galiano, San Rafael, Neptuno, Belascoaín y Reina aparecen desde los más modestos establecimientos comerciales hasta lo que más tarde serían las grandes tiendas por departamentos. Paralelamente surge gran número de establecimientos gastronómicos, variando desde los destinados a los grupos sociales de mayores ingresos hasta las sencillas fondas chinas de la calle Zanja.

Todos estos elementos condicionan una marcada estratificación social, cuyo elemento fundamental estaba dado por el status económico de sus diferentes grupos humanos, y como resultado lógico una profunda estratificación y segregación social de su espacio urbano, lo que sin dudas se refleja en las formas urbanas.

"(...) Esta era una ciudad de desproporciones, tanto en su imagen urbana y en la distribución y calidad de las viviendas como en la infraestructura y red vial, los espacios verdes, las instalaciones productivas y recreacionales (...) Con fuertes desigualdades entre centro y periferia y con un deterioro físico y social que ya había comenzado en las áreas centrales más congestionadas(...)" (Coyula, 1996), motivadas por el incesante proceso de peregrinaje urbano, como secuencia de ubicación espacio-temporal óptima de los diferentes grupos sociales a través de la historia.

En esta Habana pre revolucionaria del siglo XX es fácil apreciar la separación de los diferentes sectores sociales, polaridad que diferenció los tipos de urbanización y las variadas tipologías arquitectónicas que la distinguen en la actualidad, se distinguen en este periodo formas urbanas vinculadas al turismo y al ocio, asociadas en muchos casos a las inversiones de personajes tristemente célebres pos su vínculos con la Mafia norteamericana y el desarrollo del juego y la prostitución (Hotel Flamingo 1949; Hotel St. John's; Hotel Vedado 1951; Hotel Comodoro 1953; Hotel Colina 1954; Hotel Rosita de Hornedo 1955; Hotel Habana Riviera 1957; Hotel Capri 1957; Hotel Deauville 1958; Hotel Habana Hilton 1958).

\section{Desarrollo espacial de la ciudad a partir del triunfo de la revolución de 1959}

En enero de 1959 hace su entrada en La Habana la llamada "caravana de la victoria" como señal inequívoca de triunfo total del movimiento revolucionario liderado por el Comandante Fidel Castro Ruz, dicho triunfo marca un hito en el devenir histórico del proceso de desarrollo de las formas urbanas en la capital cubana, siendo fiel reflejo de las profundas transformaciones sociales que habrían de acometerse por parte del gobierno revolucionario.

El desarrollo espacial de la ciudad a partir de este momento se enmarca en un proceso nacional de transformaciones sociales, obedeciendo a los preceptos de una sociedad sin clases, y regida por principios de distribución equitativa por parte del Estado, condicionando, entre otros;

1. La desaparición del proceso de especulación de terrenos urbanos iii.

2. Estos cambios estructurales, dirigidos a disminuir las diferencias sociales, a dar respuesta a las nuevas necesidades sociales y a disminuir el déficit de viviendas heredados con criterio equitativo, tratan a su vez de transformar la estructura urbana existente, elemento que intercala grupos sociales diferentes, y fomenta relaciones sociales de nuevo tipo.

Se instauran planes estatales de construcción de viviendas ${ }^{\text {iv }}$; edificios de la otrora administración pública construidos en la década de los 50 como parte del nuevo centro administrativo de La Habana en torno a la plaza cívica pasan a ser sede de las entidades del nuevo poder, por ejemplo; el edificio construido como sede de la Renta de Lotería pasa a ser ocupado por el Instituto Nacional de Ahorro y Viviendas (INAV), al desaparecer ese organismo, lo ocupó la Junta Central de Planificación (JUCEPLAN), que después se llamaría Comité Estatal de Planificación, actual Ministerio de Economía y Planificación (MEP), la sede del Tribunal de Cuentas pasa a ser la sede del Ministerio de Industrias, hoy Ministerio del Interior (MININT), La Alcaldía de La Habana pasa desempeñar las funciones del Ministerios de las Fuerzas Armadas Revolucionarias (MINFAR); La edificación del Banco de Fomento Agrícola e Industrial de Cuba (BANFAIC) asume las funciones del Ministerio de Obras Públicas y posteriormente del Ministerio de la Construcción (MICONS), el Palacio de Justicia es transformado en Palacio de la Revolución y sede del Comité Central del Partido Comunista de Cuba.

Creación de numerosas instituciones culturales; Instituto Cubano de Arte e Industria Cinematográfico (ICAIC), Casa de las 
Américas, Consejo Nacional de Cultura, entre otros.

Viviendas de los grupos sociales de mayores ingresos son transformadas en sedes de entidades del nuevo gobierno, centros educacionales, guarderías infantiles, centros de salud, etc., de igual forma cuarteles militares y estaciones de policía se transforman en centros educacionales.

El sistema simbólico de la Revolución se manifiesta con fuerza también a partir de la proliferación de nuevos monumentos conmemorativos que parten de concepciones diferentes a los creados en la época prerevolucionaria, se renombran instituciones culturales haciendo referencias a sitios o mártires relacionados con el proceso revolucionario.

En cuanto a la recreación, se realiza la conversión de Clubes de descanso y recreación pertenecientes a diferentes asociaciones y grupos de poder en Círculos Sociales Obreros, cambiando desde entonces la fisonomía social de los mismos.

3. Se agrega al proceso la sucesión domiciliaria, llevada a cabo por el personal de servicios y otros en las viviendas abandonadas por sus dueños, al tomar la decisión de emigrar por temor a los efectos de las políticas radicales del gobierno revolucionario.

4. Los procesos de compactación urbana se desarrollan dado el relleno de espacios sin edificar en la trama urbana con edificios multifamiliares, la construcción de guarderías infantiles, consultorios del Plan del Médico de la Familia, policlínicas, centros educacionales y deportivos, etc.

La construcción de edificios multifamiliares unido al proceso de sucesión social a escala domiciliaria implican, de cierto modo, una mayor heterogeneidad social de la ciudad, al alterarse los componentes de la estructura social existente en el interior de diversos sectores del espacio urbano capitalino.

5. Durante 1960 y 1961 los más grandes y peores asentamientos precarios de la capital fueron demolidos, sus residentes construyeron sus propias viviendas. Los asentamientos que quedaron fueron renombrados como "Barrios Insalubres", predominando en su clasificación la calidad de la vivienda y del asentamiento, no por el status económico de sus residentes. El segundo gran esfuerzo por la eliminación y reemplazo de los asentamientos marginales se manifiesto a finales de los $60 \mathrm{y}$ principios de los 70 del siglo pasado como parte de la política oficial de creación del cinturón verde de la ciudad (Coyula, 2004).

6. En los años $70^{v}$ comienza una etapa de amplio desarrollo arquitectónico que incluye la expansión hacia la periferia de la mancha urbana a partir de la construcción de nuevos conjuntos habitacionales, centros hospitalarios, industriales, educacionales de formación vocacional en lo militar, en ciencias pedagógicas: de formación de maestros, instructores de arte, educadores de círculos infantiles, de iniciación deportiva y perfeccionamiento atlético, artísticos, tecnologías de la salud, etc.

A tenor de lo anterior, y con el interés de fomentar el crecimiento de la ciudad, primero hacia el este y más tarde hacia el oeste de la franja costera norte, se desarrollan los primeros proyectos urbanísticos en las otrora áreas destinadas al desarrollo de lujo, terrenos que, en el caso del este de la mancha urbana se habían revalorizado, luego de la inauguración del túnel submarino que eliminaba a la bahía como obstáculo natural, llevándose a cabo la urbanización, ampliación y/o remodelación de repartos o parcelaciones ya existentes.

7. De hecho, las áreas residenciales de la ciudad han estado sometidas a un continuo y variado proceso de transformaciones, que van desde su morfología, cambios funcionales, hasta la metamorfosis del régimen de propiedad y composición social, ocupacional y demográfica de sus habitantes, siendo este último quizás uno de los más persistentes, ya que las áreas residenciales de la capital, además de su lógico deterioro, han estado sometidas a intensos fenómenos de invasión y sucesión, en virtud de los cuales determinados grupos sociales han sido sustituidos por otros.

Entre los años 1986 y 1992 el movimiento de microbrigadas ejecutó obras de gran significación social para la ciudad; las instalaciones para los Juegos Panamericanos de 1991, la construcción de 133 guarderías infantiles, 25 escuelas para niños con necesidades especiales, 20 policlínicas y 46 panaderías, entre otras (INV, 2013).

¿La concepción de lograr una sociedad sin división entre clases sociales, junto con la consistente aspiración de igualar condiciones y estándares de vida, entre otros, elimina la memoria y el patrimonio urbano heredado en 1959?

Para tratar de dar respuesta a esta interrogante se debe partir de una serie de consideraciones que marcan pautas en la memoria urbana capitalina;

- En La Habana el proceso de creación del espacio urbano no ha desaparecido, existe y ha estado en constante transformación por parte de los diferentes grupos y actores sociales que lo componen.

- La asimilación del espacio urbano bajo los principios del modelo capitalista de desarrollo condicionó, y sigue condicionando la 
presencia de diferencias socio espaciales en las formas urbanas.

La existencia de diferencias espaciales "inducidas" por el estado, a partir de la sustitución de los resortes del mercado inmobiliario por la política de redistribución de inmuebles, como mecanismo de reasignación de viviendas vacantes.

La influencia del Estado resulta evidente, si se tiene en cuenta la diferencia de status que se provoca al seleccionar determinadas zonas de la ciudad, que coinciden en gran medida, con aquellas que se consideraban con mayor valor del suelo y, por ende, las más apetecidas por los grupos sociales dominantes como Zonas Congeladas, Zonas para Embajadas o de Zonas Apropiadas para el desarrollo inmobiliario, empresarial o turístico, a ello se une la socorrida política de entrega de viviendas para el personal empleado en objetivos económicos, científicos y de desarrollo social priorizados por las autoridades gubernamentales.

Las zonas marginales experimentaron un proceso de integración a la nueva sociedad, que incluyó la erradicación progresiva de los mayores barrios marginales. El proceso, si bien mejoró en muchos casos la calidad de la vivienda, no se puede asumir que se haya eliminado definitivamente la segregación urbana, ya que una buena parte de las urbanizaciones periféricas, creadas para resolver el problema de la infravivienda no se dotaron totalmente con la infraestructura de servicios comunitarios básicos, mientras otros, aparecen de manera irregular, a esos problemas se le suman los efectos de la notable desproporción locacional existente entre el lugar de residencia y los puestos de trabajo existentes, lo que supone una mayor inversión en tiempo y dinero por concepto de servicios de transporte, que deben efectuar dichas personas para acceder a los mismos.

Otra solución aplicada fue la compactación de la trama urbana a partir del relleno de los espacios no edificados en parcelaciones y urbanizaciones ya existentes, elemento que conllevó a una agudización de contradicciones, al introducirse edificaciones que en muchos casos desentonan con el contexto construido establecido en diferentes barrios residenciales, sumándose la introducción de elementos y patrones de comportamiento totalmente ajenos al lugar, lo que condiciona, que la población residente en no pocos casos no se sienta identificada con los mismos, así como que los nuevos vecinos muestren escaso sentido de pertenencia con estas áreas y poca asociación con los grupos comunitarios.

- Continuación de los procesos migratorios y el déficit de viviendas acumulado. Provoca que antiguas residencias unifamiliares en zonas de alto status social se hayan transformado en multifamiliares, a través de un proceso de subdivisión constructiva, que a veces asemejan verdaderas cuarterías ${ }^{\text {vi }}$ o casas de vecindadvii. Otras formas de resolver el problema de la vivienda ha sido aumentando el tamaño de la residencia ocupando espacio extra-residencial (Coyula, 2004, p. 7).

Las figuras del mercado y del consumo como mecanismos impulsores de la economía nacional pasan a un segundo plano al institucionalizarse la distribución centralizada y equitativa de productos industriales y alimenticios, generando efectos que se han podido apreciar de manera conjunta en el sector de la gastronomía, ya que al no considerarse sectores estratégicos de la economía según nuestra apreciación, se asiste a un paulatino proceso de disminución de la infraestructura existente, ya sea por deterioro físico continuado o por efectos del cambio de uso, al transformarse una buena parte de ellas en viviendas unifamiliares, oficinas de entidades estatales, almacenes, etc. , situación que con la irrupción de la crisis económica de los años 90 agudiza aún más el proceso de deterioro físico y la pérdida de infraestructura existente, en muchos casos de carácter patrimonial.

\section{La década de 1990 , nueva etapa de reorientación económica, aparición de nuevos actores y gestores en función del desarrollo}

A partir de los años 90 del siglo pasado, los efectos conjuntos de la desaparición del bloque socialista de Europa del este, y de su mecanismo de integración económica, unido al recrudecimiento del bloqueo económico y financiero decretado por el gobierno de los Estados Unidos de Norteamérica contra Cuba desde el año 1962, y, en tercer lugar, por lamentables e innegables errores estructurales y de toma de decisiones cometidos en nuestro país a lo largo de estos años de revolución, determinan que la economía cubana se sumergiera en una profunda crisis económica, la cual, produce gravísimas afectaciones en el sistema económico y social y, por ende, en el patrimonio edificado de la capital, ya deteriorado con anterioridad, constituyendo una apreciable afectación a la calidad de vida de la población, favorecida hasta entonces con un alto grado de homogeneidad por el sistema social creado a partir de 1959.

Ante esta situación, el gobierno se ve en la necesidad de promulgar una serie de medidas económicas ${ }^{\text {viii }}$, con la finalidad de sortear la crisis y salir airoso de la misma, constituyendo las mismas un gran reto para el país, y por ende para la capital, 
dado que, aunque indeseado, se asiste inevitablemente a un proceso de acentuación y reacondicionamiento de la diferenciación socio espacial, incluyendo las formas urbanas.

El modelo cubano para salir de la crisis ${ }^{\text {ix }}$, presenta matices que lo hacen peculiar en su impacto sobre la estructura socio espacial y de las formas urbanas en la ciudad:

1. Siempre ha tenido en cuenta y ha tratado de sortear los efectos nefastos de la globalización neoliberal,

2. Voluntad política expresa del gobierno de no subordinar el destino de sus ciudadanos más desfavorecidos a las leyes internacionales del mercado, a lo que se une,

3. El estar obligado a luchar bajo el pertinaz hostigamiento económico y político del gobierno de los Estados Unidos de Norteamérica.

No obstante estas consideraciones, se provocan de inmediato transformaciones en la organización del espacio urbano dado por;

I- La presencia de nuevas tecnologías, actores, gestores y actividades, tanto sociales, como económicas, haciendo referencia, por ejemplo, al modelo de desarrollo territorial seguido con los espacios innovadores, entre los que se destacan las edificaciones del Polo Científico levantadas hacia el oeste de la mancha urbana.

II- El desarrollo del sector inmobiliario, en zonas de la ciudad con presencia de infraestructura urbana y condiciones ambientales favorable; el que incluye casos puntuales de conjuntos habitacionales cerrados.

III- La creación de nuevas áreas y centros comerciales; así como de zonas de desarrollo empresarial, zonas francas, etc. ${ }^{\mathrm{x}}$.

IV- El centro urbano tradicional tampoco escapa a los efectos de la reestructuración socio espacial: Con la despenalización de la tenencia de moneda libremente convertible en los años más difíciles de la crisis, comienzan a surgir sociedades comerciales, interesadas en las instalaciones (comerciales, gastronómicas y de servicios) situadas en los principales ejes viales de la ciudad, elemento que permite rescatar, una serie de inmuebles que estaban faltos de reparación o en abandono total por carencia de recursos. Con el transcurso del tiempo, estas entidades económicas han comenzado a extenderse por diversos ejes de la ciudad, llegando incluso hasta escala de barrio.

$\mathrm{V}$ - Este proceso de recuperación del centro urbano tradicional, a diferencia del casco histórico fundacional, no implica necesariamente una mejoría en todos sus inmuebles, puesto que, de forma general solo se reparan las instalaciones que se les asigna con fines comerciales, sin que frecuentemente se produzcan acciones constructivas en las edificaciones aledañas, elemento que provoca diferencias, dados los contrastes visuales que se producen, entre estas instalaciones remodeladas, con buena imagen y diversidad de productos en oferta, y el total deterioro, y desabastecimiento, de las edificaciones e instalaciones comerciales adyacentes,

VI- Dentro del centro tradicional, y cerca de uno de sus ejes viales principales, se lleva a cabo otro de los más relevantes procesos de re asimilación socio espacial y de recuperación de la memoria histórica, a través del "Grupo Promotor del Barrio Chino", el cual ha impulsado la búsqueda y rescate del patrimonio edificado, las tradiciones, costumbres, cultura, y otros aspectos del modo de vida de este otrora foco de actividad económica, caracterizada por la idiosincrasia del asiático, su laboriosidad, y su tenacidad.

VII- El cambio de uso de la infraestructura concebida como residencial, hacia el comercial, servicios y, el de asentamiento de representaciones comerciales extranjeras, en zonas históricamente favorecidas de la ciudad (Los municipios Playa y Plaza de la Revolución concentran aproximadamente el $75.0 \%$ de las sedes de las representaciones comerciales foráneas destacadas en la capital).

VIII- Auge constructivo de instalaciones hoteleras y extra - hotelera para el desarrollo del turismo como sector emergente.

IX- La Irrupción en la trama urbana de centros de recreación selectivos, especializados, y diferenciados, así como de desarrollos turísticos, en los que si bien no está prohibido explícitamente al acceso público, la presencia de barreras visuales, y de acceso, permiten que la población perciba esta situación como un proceso de privatización del espacio público, sobre todo por la presencia de guardia de seguridad especializada.

$\mathrm{X}$ - Terciarización de la zona del centro histórico, a partir de la remodelación y reconstrucción de hoteles, bares, restaurantes y cafeterías allí localizados, todo esto con la perspectiva de aprovechar el patrimonio histórico edificado, reflejando mucha de esta infraestructura turística cierto aire nostálgico de La Habana prerevolucionaria, a lo que se une la remodelación de edificaciones para el sector empresarial, entre otros.

A raíz de la crisis de los 90, la economía local comienza a dar un giro importante, pues al apostarse al desarrollo del turismo internacional como impulsor de la economía nacional se convierte el Centro Histórico de La Habana en un importante polo turístico

La Habana, como principal centro urbano del país y en especial su Centro histórico fundacional reciben importantes volúmenes de visitantes y turistas al año, siendo importantes exponentes de su identidad física y social la rica 
variedad de formas urbanas que como edificaciones conforman un recurso patrimonial que se transforma en un fuerte atractivo turístico. El creciente consumo de estos productos turísticos en ocasiones obliga a que en aras de lograr una mayor diversidad de ofertas se produzcan reinvenciones y transformaciones de las formas urbanas preexistentes.

XI- Este proceso de recomposición social, ha acentuado el proceso de deterioro del fondo habitacional, y de infraestructura urbana, en sectores menos favorecidos de la ciudad, dada la carencia de recursos por parte del estado para darle solución inmediata a los problemas sociales más apremiantes, entre los que se destacan, el mal estado de sus viviendas $(27.0 \%$ en regular estado técnico según el Instituto Nacional de la Vivienda (INV, 2013), y vías de comunicación.

XII- Crecimiento y surgimiento de nuevos asentamientos insalubres (En La Habana, en 2011 existían 151 asentamientos precarios con una población de 75215 habitantes (DPPF, 2011). Con respecto a 1996 (CEDEM, 1998) se produce un incremento de 18 barrios precarios. Este proceso, también ha repercutido a escala personal, y familiar, generándose en lo social, la aparición de cambios en las estrategias de vida familiar, que a su vez, mediante los proceso de cambio de uso muestran impactos, tanto positivos, como negativos en el paisaje urbano, entre los que se encuentran:

1- En zonas históricamente favorecidas bajo los preceptos de las leyes del mercado

a) Los generados por la presencia del trabajo por cuenta propia:

Através de la renta de habitaciones al turismo internacional en viviendas particulares;

La conversión de fachadas, habitaciones o portales de residencias en pequeños restaurantes familiares o cafeterías llamados popularmente Paladares;

La transformación de jardines en domicilios familiares para el desarrollo del servicio de estacionamiento rentado para autos, motos, y bicicletas, así como de cafeterías en zonas cercanas a algún centro comercial o vinculado al turismo internacional;

La autorización del Mercado Agropecuario bajo los preceptos de las leyes del mercado ha sido otras de las transformaciones ocurridas en la economía que han repercutido en la forma e imagen urbana.

b) Los generados por la presencia del sector empresarial:

El referido a la transformación de antiguas residencias en centros comerciales, antiguas tiendas, bodegas, cafeterías, y demás convertidas en sedes de oficinas burocráticas, la irrupción en la trama urbana de centros corporativos, conjuntos habitacionales cerrados, centros de recreación selectivos, especializados y diferenciados, así como de desarrollos turísticos.

En general se producen transformaciones en la organización del espacio urbano dada la presencia de nuevas tecnologías, actores y actividades, tanto sociales como económicas, generando nuevas formas arquitectónicas y urbanas, en algunos casos constituyéndose en verdaderas contradicciones paisajísticas con el entorno.

c) Proceso paralelo de recomposición social del sector residencial:

Se aprecia ya en estas zonas favorecidas el fenómeno de la bunkerización o amurallamiento domiciliario convirtiéndose en un proceso de creación de barreras visuales, y de acceso. se puede agregar que, si bien el enrejado de los ventanales ha sido un recurso tradicional, y de muy buen gusto desde la arquitectura colonial y republicana, su irrupción desmedida en la época actual en ventanales, puertas, y jardines, denota diferencias sociales perceptibles espacialmente, tanto en su concepción de diseño, como en el material de ejecución.

Esta irrupción (en muchos casos desmedida) del amurallamiento domiciliario si bien en sus inicios puede interpretarse como formas generadas por la geografía del miedo o del delito, también puede relacionarse con un renacer del reconocimiento del sentido del valor de la propiedad privada familiar, o de la necesidad de privacidad hogareña y/o para los negocios.

d) Ciertos grupos sociales, por su poder adquisitivo (independientemente de su origen), comienzan a valorar, las externalidades positivas, y negativas de su lugar de residencia (a pesar de no existir un mercado inmobiliario formal), asumiendo la posibilidad de cambio de tipo de domicilio y de sector de residencia en la ciudad según su "status" social, provocando en muchos casos un proceso de recomposición social residencial en determinadas zonas de la ciudad.

\section{2- En zonas no favorecidas}

No debe olvidarse, por su trascendencia, que producto de los efectos diferenciados de la crisis a escala nacional, se produce un boom migratorio hacia la capital, el cual, unido al déficit de viviendas acumuladas, contribuye en gran medida a un proceso de precarización de la vivienda, el cual, si bien presenta manifestación 
acentuada en determinados sectores de la urbe, no excluye la presencia del mismo a todo lo largo y ancho de la misma, haciéndose acompañar de procesos de cambios de uso de determinados inmuebles, entre los que se destacan, la conversión de antiguas tiendas, y bodegas, en hogares, y la mutilación de fachadas, balcones, azoteas y áreas de estacionamiento en inmuebles, con la finalidad de ampliación de su espacio habitable.

En este proceso, al igual que en periodos anteriores, los inmigrantes han tenido la capacidad de desarrollar estrategias de redefinición de ellos mismos, de sus lugares de salida, y de sus nichos de llegada a la ciudad, al tiempo que, como se ha mencionado anteriormente, han contribuido también a la redefinición de la urbe en su conjunto.

Siendo el resultado final, no la constitución de una nueva ciudad relativamente homogénea, y uniforme, sino, más bien, de otra ciudad más heterogénea y diversa.

Las medidas adoptadas para salir de la crisis han tenido indudables impactos en la vida y la fisonomía de la ciudad. La expansión de la economía estatal y del sector no estatal ha generado una mayor diversidad de la oferta turística, comercial, gastronómica, habitacional, del transporte, pero también, a la par de la actividad estatal una evidente degradación urbanística, la que incluye invasiones del espacio público, cambios de uso, así como agresiones a la estética urbana mediante cambios y mutilaciones de fachadas y espacios interiores.

Por otra parte, la base económica de la capital ha sufrido, además, una radical transformación por la fuerte descapitalización y obsolescencia tecnológica de una buena parte de la planta industrial, de almacenaje y de transporte (García, 2014).

A partir de 2011, y dándole respuesta a los múltiples "Lineamientos de la Política Económica y Social del Partido y la Revolución" aprobados por el VI Congreso del Partido Comunista de Cuba (PCC, 2011) en abril de ese mismo año con el fin de implementar el proceso de "Actualización del modelo económico cubano" se han desarrollado una serie de modificaciones a las legislaciones vigentes que han reafirmados y marcado nuevas tendencias en el proceso de renovación y creación de formas urbanas.

Modificaciones a las Leyes de la Vivienda, Migratoria, de Cooperativas, entre otras, han generado el autorizo de la compra-venta de viviendas y autos, la liberalización de los viajes al exterior y mayor apertura hacia los cubanos residentes en el extranjero y al trabajo por cuenta propia, incluyéndose su diversificación, la creación de Cooperativas no agropecuarias, mercantilización de numerosos servicios en diversos sectores de la economía, como el transporte, el comercio, la cultura, la "formalización" del sector informal, la potenciación del sector turístico, etc., realidades que llevan aparejado la renovación y aparición de nuevas y diversas formas urbanas en cuanto a diseño y calidad a partir de una creciente heterogeneidad y estratificación social.

Esta nueva etapa se constituye sin dudas en un nuevo e interesante reto para los investigadores y para los tomadores de decisiones en el ámbito del urbanismo para la capital cubana.

En el caso cubano, y en su extensión la ciudad capital, si bien ha sido genuino aspirar a la igualdad espacial de oportunidades, como contraparte a los desbalances espaciales heredados y emergentes, las políticas públicas no han podido cumplir a cabalidad su ideario, no por debilidad de sentido, ni de dirección, ni de interés de las mismas, sino por la debilidad financiera que sufren por carencia de recursos para ejecutarlas, no obstante, constituyen ejemplos del rol del Estado y de la voluntad política del "querer hacer cuando se puede hacer" la construcción y extensión por toda la ciudad de nuevas formas urbanas: servicios primarios de atención de salud, como son los Consultorios - viviendas del Plan del Médico de la familia (incluso en los barrios precarios) y los servicios médicos especializados en las policlínicas a escala de áreas de salud, la dotación equitativa de servicios educacionales a todos los niveles, incluyéndose la creación de Sedes Universitarias Municipales, la implementación de los Joven Club de Computación, las Casas de Cultura con sus proyectos comunitarios, la creación y funcionamiento de los Talleres de Transformación Integral del Barrio (TTIB), etc.

\section{Reflexiones finales: ciudad, memoria y turismo en el centro histórico de La Habana}

En Cuba, a raíz de la crisis de los 90 la economía local comienza a dar un giro importante, pues al apostarse al desarrollo del turismo internacional como impulsor de la economía nacional se convierte el Centro Histórico de La Habana en un importante polo turístico, apelándose a la memoria existente y al simbolismo existente en su patrimonio histórico edificado, muy vinculado a la época de la colonia española, con edificaciones construidas en su mayoría durante los siglos XVIII y XIX.

Comienza entonces el rescate del ambiente histórico de la Habana Vieja, impulsado por la oficina del historiador de la ciudad.

Esta atractiva Habana, heterogénea y diversa, con sus manchas y luces, la que tanto 
busca el turista es el resultado de la combinación de diversos factores, por un lado el efecto de las transformaciones políticas y sociales ocurridas después de 1959, proceso que llevo aparejado la detención en el tiempo del crecimiento sucesivo de la capital en función de extender las bondades del sistema al resto del país con la re funcionalización de numerosas edificaciones y la construcción prioritaria de centros educacionales, hospitalarios, deportivos, científicos, de servicios y recreativos, entre otros.

La pérdida de memoria histórica edificada a que fueron sometidas no pocas ciudades a escala planetaria en pos de la "modernidad" no pudo avanzar mucho en La Habana después de 1959, no poseer una economía potente y tratar de desarrollarnos a pesar del constante asedio y bloqueo económico y comercial de la principal potencia económica del mundo ha permitido salvaguardar el rico y variado patrimonio existente de los dictámenes y resortes naturales asociados al accionar de las leyes del mercado inmobiliario.

¿Qué papel ha desempeñado el turismo en la conformación actual de esas formas y memorias?

¿Turismo como consumidor de esas formas y memorias?

¿Generan desarrollo social esas nuevas formas vinculadas al desarrollo turístico?

El turismo no es una actividad nueva en Cuba, desde el siglo XVI la villa de San Cristóbal de La Habana recibía arribos de forasteros, mercaderes y marinos, que fueron perfilando la personalidad urbana y el ambiente de la ciudad. En la etapa colonial, al convertirse la villa en puerto de escala obligada de las embarcaciones en su viaje hacia y desde España, se potenciaron los servicios de alojamiento y gastronomía en el territorio (Cruz, 2017).

El desarrollo del comercio y los arribos de inmigrantes y visitantes extranjeros a la isla generaron una demanda de alojamiento, a la que le sucedió la aparición de teatros, cafés, salas de bailes, paseos y parques con bandas de música, entre otras edificaciones destinadas a usos culturales y comerciales.

Al igual que en el resto del mundo, su mayor auge se da a partir de los años 50 del siglo pasado. Es en esa época, cuando el desarrollo turístico en la mayor de las Antillas estuvo muy ligado a la presencia de la mafia norteamericana en la Isla, Estados Unidos era el mercado principal, y el juego y la prostitución eran las principales ofertas de la Isla.

A partir de 1959, como ya se ha explicado, el desarrollo de la economía estuvo dirigido a otros programas importantes del país, por lo cual el turismo era entonces fundamentalmente nacional, hecho que condicionó una estructura habitacional poco competitiva como producto internacional.

La década de los años 80 da comienzo a una reapertura al turismo internacional, pero no es hasta los noventas que se produce un nuevo enfoque del desarrollo de este sector, se crean las primeras empresas mixtas y hay un crecimiento acelerado en los arribos de visitantes y en los ingresos.

La promoción turística en Cuba se ha fundamentado en el turismo de sol y playa, no siendo la prioridad en sus inicios el tener en cuenta los elementos patrimoniales de las ciudades (herencia urbanística, arquitectónica y artística) como verdaderos recursos turísticos.

La Habana es la principal ciudad del país, recibe flujos continuos de turistas $y$ visitantes durante todo el año; en especial su Centro Histórico, que según estimaciones acoge cerca del $90 \%$ de sus visitantes, ya sea en excursiones organizadas por los receptivos o de forma individual, consumiendo el territorio de disimiles maneras.

El Centro Histórico de la Habana es exponente y símbolo de la identidad física y espiritual de la ciudad que identifica, en correspondencia con sus núcleos fundacionales y tradicionales. El mismo ostenta una rica variedad de edificaciones que forman un recurso patrimonial y la convierten en un atractivo turístico cuya explotación redunda en un incremento en su desarrollo económico y social.

Monumento Nacional desde 1978 y declarado Patrimonio de la Humanidad por la UNESCO en 1982 ha venido teniendo desde entonces un sostenido proceso de restauración que ha devuelto a varios sectores su antiguo esplendor, siendo su principal responsable la oficina del Historiador de la Ciudad de La Habana $(\mathrm{OHCH})$, quien a través de un modelo de gestión empresarial ${ }^{x i}$ que apela a procesos autofinanciados y criterios integradores de los recursos disponibles y la rentabilidad económica en pos de la sostenibilidad además ha trabajado para la mejora de la calidad de vida de la población local y la toma de conciencia popular respecto a la participación ciudadana en la localidad. Un total de 25 instalaciones hoteleras reflejan la importancia creciente del turismo en el territorio.

Para tener en cuenta la importancia que se le asigna a la memoria y las formas urbanas en el emprendimiento turístico baste mencionar el Esquema de Ordenamiento territorial y Urbano de La Habana, elaborado en diciembre de 2012 (DPPF, 2012), el cual entre las premisas para desarrollar las proyecciones "Habana, siglo XXP" plantea la necesidad de sustentarse en la dimensión sociocultural de una ciudad preservada del auge 
desarrollista, en la cual su patrimonio cultural (material e intelectual) constituya la base para su transformación, debiendo contener la ciudad proyectada para el siglo XXI la del XX, XIX y del XVIII pero con enfoque del XXI.

En dicho documento y como objetivos para el desarrollo de La Habana se plantea como número uno, entre otros, aprovechar su reconocido patrimonio urbano, así como revertir el deterioro de las aéreas centrales preservando su valioso patrimonio cultural.

En el tema referido a la ciudad productiva, con respecto al desarrollo del turismo se plantea: Consolidar y diversificar el producto turístico nacional e internacional aprovechando las potencialidades de la ciudad, a lo que se une el fortalecer la infraestructura hotelera y extrahotelera.

Por último, en el tema Patrimonio, imagen urbana, diseño de La Habana, patrimonio cultural de la nación, se hace referencia a la necesidad de su preservación y de la salvaguarda de su imagen, el partir de un enfoque de máxima preservación en toda visión presente o futura de la ciudad y el elaborar una estrategia de intervención de las áreas de mayor valor patrimonial, siempre teniendo en cuenta su peligro de perdida, tratando siempre de desarrollar procesos sostenibles en lo económico, en lo social, cultural y ambiental.

La potenciación del sector turístico en las últimas décadas en el Centro Histórico de La Habana, ha creado realidades que llevan aparejado a la restauración y aparición de nuevas y diversas formas urbanas la re funcionalización de las memorias urbanas, elementos que se constituyen en interesantes temas de investigación para la geografía, así como de retos para los gestores del tan célebre espacio urbano.

La actividad turística se inserta en un proyecto de rehabilitación integral en el que se garantiza la participación de los ciudadanos a través de la generación de empleo y la mejora de sus condiciones de vida. De este modo, se establece una alianza entre los servicios turísticos y el entorno comunitario.

Se trata en definitiva de ofrecer al visitante tanto una información como una vivencia (ver, explorar, observar, sentir, vivir y revivir el patrimonio), en fin establecer una comunicación visitante- patrimonio.

El modelo de gestión desarrollado en el Centro Histórico de La Habana, genera condiciones favorables para aplicar políticas públicas que permiten el desarrollo del territorio y el mejoramiento de la calidad de vida de la población, dan fe de esta situación la generación de más de 13.000 empleos directos y otros 2.000 indirectos en los sectores de la construcción, el turismo y la cultura, conllevando un incremento de los ingresos de los residentes locales, quienes representan el 50\% de los empleados (Leal, 2005).

Se trata entonces, según Echarri (Echarri, 2006) de respetar y valorar el pasado pensando en un futuro sostenible; no basta el hecho de vender patrimonio sino de valorizarlo tanto para la sociedad local como para la foránea, promocionándolo en estrecha relación con los procesos productivos, la creación de empleos, la innovación tecnológica y la generación de ganancias.

\section{Notas}

i Conocida también como Solar o Cuartería, se caracteriza por ser una edificación dedicada a la renta de habitaciones, la misma se estructura con un patio central y determinado número de habitaciones a su alrededor, siendo común el servicio de agua y servicio sanitario, aunque en algunos casos este último podía estar al interior de la vivienda.

ii El llamado Centro urbano Tradicional, tuvo su origen en la segunda mitad del siglo XIX a partir de los terrenos libres producto de la demolición de las murallas y se desarrolló plenamente hasta 1960 como consecuencia del violento auge de la actividad comercial establecida en las principales avenidas, aprovechando las ventajas climáticas que ofrecen los portales para la circulación peatonal y la continuidad espacial que las calles San Rafael y Neptuno ofrecen a Obispo y O Relly, anteriormente conformados. La zona de centro de ciudad, está constituido parcialmente por el Centro Tradicional de la capital. Su estructura está conformada por 7 ejes viales fuertes, unidos entre sí por una trama urbana muy compacta y densamente urbanizada.

iiiLa ley de reforma urbana de octubre de 1960 estableció el concepto de "la vivienda como un servicio público", estableciéndose 2 formas básicas de tenencia, "propietario" y "Usufructuario" en las "viviendas propiedad del estado", los propietarios individuales no deben tener más de una vivienda permanente y una de vacaciones. Los individuales pueden comprar edificaciones y terrenos, pero solo el gobierno puede sentar los precios, aunque este último tiene la primera opción para comprar.

iv Se ponen en marcha Planes y Proyectos de viviendas como bien social accesible a todos los sectores de la población.

vA partir del 17 de marzo de 1971 se crea el Movimiento de Micro brigadas como fórmula para incorporar a los trabajadores a la construcción de viviendas ante la carencia de fuerza de trabajo en las entidades constructoras estatales. Según el Instituto Nacional de la Vivienda (INV, 2013), Este movimiento edificó en La Habana unas 60000 viviendas entre 1971 y 1985. 
vi Cuartería: Gran mansión o antiguo hotel o casa de huéspedes subdividida en habitaciones, frecuentemente por encima de las 60 familias.

vii Casa de vecindad: Pequeñas subdivisiones realizadas a viviendas individuales, generalmente con 12 habitaciones o menos.

viii Ante la situación creada el gobierno cubano adoptó un programa de emergencia económica denominado "Plan de Período Especial en Tiempo de Paz", el cual incluyó un conjunto de medidas orientadas a tratar de atenuar, en un primer momento, y luego, reducir paulatinamente el impacto de dicha situación sobre la población, así como priorizar las acciones que contribuyeran a superar la crisis y promover el proceso de recuperación del desarrollo.

ix Este modelo incluye la despenalización de la tenencia y uso de divisas libremente convertibles en transacciones minoristas a los ciudadanos cubanos a partir del Decreto Ley 140 del año 1994, creación de las casas de cambio de moneda (CADECA) en octubre de 1995, la autorización del trabajo por cuenta propia y de la recepción de remesas familiares, la apertura al capital extranjero y el desarrollo del turismo.

x Todo esto a tenor de la aprobación en 1995 de la Ley \# 77 “Ley para la Inversión Extranjera” y en junio de 1996 la creación de las Zonas Francas y Parques Industriales; completándose con esta medida la cobertura legal para la inversión de capital extranjero y el desarrollo del comercio.

x Se aplicó un nuevo modelo de gestión a partir de su reconocimiento como Zona Priorizada para la Conservación mediante el decreto Ley 143 de octubre de 1993, y como Zona de Alta Significación para el Turismo por el Acuerdo 2951 del Consejo de Ministros, de noviembre de 1995

\section{Referencias bibliográficas}

Altshuler, J. (1990). Las 30 horas de Einstein en Cuba. Recuperado de http://www.schct.sld.cu/publicaciones/Einst ein30-Espanol.pdf

CEDEM (1998). Asentamientos insalubres en Ciudad de La Habana. Hallargos y recomendaciones. $\mathrm{La}$ Habana: CEDEM

Coyula, M. (1996). La Habana Siempre, siempre mi Habana. Archivos de Arquitectura Antillana, 1 (2), pp. 77-83.

Coyula, M. \& Hamberg, J. (2004). Understanding slums: The case of Havana, Cuba. The David Rockefeller Center for Latin American Studies. Working papers on Latin American, 4, pp. 5-4.
Cruz, N. (2017). El modelo de gestión del Centro Histórico La Habana Vieja. Logros y desafíos. (Cuaderno técnico). Plan Maestro, OHLH.

Dirección Provincial de Planificación Física (2011). Barrios y focos precarios de la provincia "La Habana". La Habana: DPPF.

Dirección Provincial de Planificación Física (2012). Esquema de Ordenamiento Territorial y Urbano. La Habana: DPPF.

Echarri, M. (2006). Análisis geográfica del turismo en ciudades patrimoniales cubana. Caso de estudio. Centro Histórico de La Habana (Tesis Doctoral). Universidad de La Habana, Facultad de Turismo, Cuba.

García, C. (2014). La Habana, ¿una ecuación imposible? Catalejo. El Blog de Temas. Recuperado de http://www.temas.cult.cu/node/1988

Instituto Nacional de la Vivienda (2013). Estrategia para el desarrollo habitacional de La Habana "2011 - 2030". La Habana: INV

Leal, E. (2005). Patrimonio tangible e intangible dos ópticas, un mismo reto. Recuperado de http://urbo.ovpm.org.

Partido Comunista de Cuba (2011). Resolución sobre los lineamientos de la Politica Económica y Social del Partido y la Revolución. La Habana: PCC.

\section{Cómo citar este artículo}

Rego, R. G. (2018). La Habana, dinámica socio espacial de las formas urbanas. PatryTer, (1), 1, pp. 1-12.

DOI: https://doi.org/10.26512/patryter.v1i1.7100 